\title{
Prevalence and Correlates of Hypertension among Adults Aged 25 Years or Older in a Mining Town of Kitwe, Zambia
}

\author{
Seter Siziya ${ }^{1 *}$, Emmanuel Rudatsikira ${ }^{2}$, Olusegun Babaniyi ${ }^{3}$, Peter Songolo ${ }^{3}$, David Mulenga ${ }^{1}$ and Adamson S Muula ${ }^{4}$
}

${ }^{1}$ Department of Clinical Sciences, Public Health Unit, Copperbelt University, Ndola, Zambia

${ }^{2}$ School of Health Professions, Andrews University, Berrien Springs, Michigan, United States

${ }^{3}$ World Health Organization Country Office, Lusaka, Zambia

${ }^{4}$ Department of Community Health, University of Malawi, College of Medicine, Blantyre, Malawi

\section{Abstract}

Background: Hypertension is a major risk factor for cardiovascular disease. The trend towards a higher burden of non-communicable chronic diseases in developing countries is of great concern as it adds to the burden of communicable diseases. The aim of this study was to estimate the prevalence and correlates of hypertension among adults in the City of Kitwe, Zambia.

Methods: A modified WHO STEPs (STEPwise Approach to Surveillance) method was used to collect data through a community-based survey among persons aged 25 years or older living in urban Kitwe, Zambia. Prevalence of hypertension was estimated and compared between males and females. Odds ratio (OR) and adjusted odds ratio (AOR) and their $95 \%$ confidence intervals were used to establish associations between exposure factors and hypertension.

Results: Altogether, 1627 persons participated in the survey of which $57.7 \%$ were females. Overall, $32.3 \%$ (33.5\% of males and $31.1 \%$ of females, $p=0.350$ ) were hypertensive. Age and body mass index were significantly associated with hypertension. Compared to participants who were of age 45 years or older, participants who were below the age of 45 years were less likely to have hypertension ( $A O R=0.53,95 \% \mathrm{Cl}[0.45,0.62]$ ) for 25-34 years age group, and $\mathrm{AOR}=0.61,95 \% \mathrm{Cl}[0.50,0.74])$ for $35-44$ years age group). Participants who had $\mathrm{BMI}$ of less than $18.5 \mathrm{~kg} / \mathrm{m}^{2}$ were $50 \%(\mathrm{AOR}=0.50,95 \% \mathrm{Cl}[0.32,0.77])$ less likely to have hypertension compared to participants who had BMl of $30 \mathrm{~kg} /$ $\mathrm{m}^{2}$ or more. Meanwhile, participants who had BMI of $25.0-29.9 \mathrm{~kg} / \mathrm{m}^{2}$ were $33 \%(\mathrm{AOR}=1.33,95 \% \mathrm{Cl}[1.05,1.69] \mathrm{more}$ likely to have hypertension compared to participants who had BMI of $30 \mathrm{~kg} / \mathrm{m}^{2}$ or more.

Conclusions: Our findings indicate that hypertension is prevalent among urban residents in Kitwe, Zambia. Effective prevention strategies including interventions to ensure lower BMls, should be implemented, taking into considerations the risk factors identified in this study.

Keywords: Hypertension; Prevalence; Correlates; Mining town; Kitwe; Zambia

\section{Introduction}

Hypertension is prevalent all around the world; one in three adults lives with hypertension [1]. Hypertension is a major risk factor for cardiovascular disease [2], which is the leading cause of death among older Africans. The burden of cardiovascular disease is estimated to be twice as high in 2020 as it was in 1999 with severe negative impact on the economic development in many ways, including the high cost of treatment, limited productivity and increase in inequalities [3,4]. Noncommunicable chronic diseases (NCDs) impose a heavy burden in sub-Saharan Africa in addition to communicable diseases [5]

Risk factors for hypertension include increasing age [6-8], low education $[9,10]$, obesity [11], sedentary lifestyle [12], family history [13], smoking [14], alcohol use [15] and diet [16]. The trend toward a higher burden of chronic diseases in low income countries is of great concern as it adds to the burden of infectious diseases. The aim of this study was to estimate the prevalence and correlates of hypertension among adults aged 25 years or older in the City of Kitwe, Zambia. Knowledge of the burden of hypertension may contribute to general awareness of the problem, but also inform the design and implementation of public health interventions and healthcare services.

\section{Methods}

Details of the methods that were used in the survey are similar to those described for Lusaka and reported by Goma et al. [11],
Nsakashalo-Senkwe et al. [17] and Siziya et al. [18]. We highlight briefly the methods that were used in the survey below.

\section{Setting and design}

The study was conducted in Kitwe district in Copperbelt province of Zambia. A cross sectional study using a modified World Health Organization (WHO) global NCD surveillance initiative, NCDSTEPwise approach STEPs 1 and 2, was used in the study [19]. The WHO STEPwise approach is a standardized population-based survey of adults aged 25-64 years that estimates prevalence rates and correlates for chronic diseases. The STEPs questionnaire has three sections arranged in a stepwise order. The first step covers behavioral factors, the second covers physical measurements and the third step covers biochemical measurements. WHO recommends that most countries undertake steps 1 and 2 . Steps 1 through to 3 are recommended for well-resourced countries.

*Corresponding author: Seter Siziya, Department of Clinical Sciences, Public Health Unit, Copperbelt University, Ndola, Zambia, Tel: +260955752646; Fax: +260212618511; E-mail: ssiziya@gmail.com

Received March 20, 2012; Accepted July 09, 2012; Published July 12, 2012

Citation: Siziya S, Rudatsikira E, Babaniyi O, Songolo P, Mulenga D, et al. (2012) Prevalence and Correlates of Hypertension among Adults Aged 25 Years or Older in a Mining Town of Kitwe, Zambia. J Hypertens 1:105. doi:10.4172/2167. 1095.1000105

Copyright: $\odot 2012$ Siziya S, et al. This is an open-access article distributed unde the terms of the Creative Commons Attribution License, which permits unrestricted use, distribution, and reproduction in any medium, provided the original author and source are credited. 


\section{Sample size and sampling}

A sample size of 1620 was determined using a prevalence rate of $50 \pm 5 \%$, a design effect of 2 , a $95 \%$ response rate; and assuming an infinitely large population to sample from. A multi-stage sampling technique was used to sample the participants. Kitwe was divided in five constituencies (two comprising high costs residential areas, and three low cost residential areas). Firstly, we randomly selected one out of the two high cost residential areas, and also selected two out of the three low cost residential areas. Secondly, from each selected constituency 1 ward was selected. Thirdly, we selected six Census Supervisory Areas (CSAs) from the low cost residential areas, and four CSAs from the high cost residential area. Fourthly, one Standared Enumeration Area (SEA) was selected from each CSA. In total 10 SEAs were selected for the study. SEAs were selected using a systematic random sampling method. Finally from the selected SEAs, households were systematically sampled. All individuals (male or female) aged 25 years or older in a selected household were eligible to participate in the study. If a selected household did not have an eligible person, it was not replaced. Interviewers moved to the next household that was originally sampled.

\section{Data Collection}

\section{Interviews}

An interview schedule was used to collect some data from the interviewees. The questionnaire was divided into the following sections among others: demographic information, tobacco use, alcohol consumption, sedentary behaviour, and history of raised blood pressure. Biological measurements (Height and Weight, Waist, Blood pressure, Hip circumference and Heart rate) were measured by trained research staff.

\section{Measurements}

We used the WHO STEPwise method [19] of showing cards to explain the meaning of some of the terms in obtaining the measurements.

\section{Blood pressure}

The Omron Digital Automatic BP Monitor M4-1 (OMRON Healthcare Europe BV, The Netherlands) was used to measure the blood pressure of the participants. Participants rested for three minutes in between three successive readings of blood pressure. An average of the three readings was considered the final reading for blood pressure [11].

\section{Height}

Height was measured in centimeters without the participant wearing foot or head gear. The Seca Brand 214 Portable Stadiometer (Secagmbh \& Co. kg Hamburg, German) was used to measure the height.

\section{Weight}

Weight was measured in kilograms using the Heine Portable Professional Adult Scale 737 (Secagmbh \& Co. kg Humburg, German). Participants were asked to stand still, face forward, and place arms on the sides of the body.

\section{Waist circumference}

The measurement for waist circumference was taken in a private area using a Figure Finder Tape Measure. The tape measure was wrapped around the waist at the midpoint between the inferior margin of the last rib and the crest of the iliac, and the measurement was recorded in centimeters.

\section{Hip circumference}

The measurement for hip circumference was taken in a private area using the Figure Finder Tape Measure, and was recorded in centimeters. The tape measure was placed over the buttocks at the maximum circumference.

\section{Heart rate}

The heart rate was recorded using the ORMRON digital automatic blood pressure monitor M4-1 (OMRON Healthcare Europe BV, The Netherlands).

\section{Data Management}

Two data entry clerks were trained to enter the data using Epi Data software. Data were double entered and validated. The data entry template had consistency and range checks embedded in it. The validated data was exported to SPSS version 11.5 for analysis.

\section{Definitions}

Body mass Index (BMI) was categorized as $<18.5$ (underweight), 18.5-24.9 (normal weight), 25.0-29.9 (overweight), and 30+ (obese); waist-hip ratios was grouped into two: $<1$ (normal) and $>1$ (raised); blood pressure of more than $140 / 90$ was considered to indicate hypertension. Participants who were on antihypertensive medication were also included in the high blood pressure group [18].

\section{Data Analysis}

Proportions of the outcome variables and socio-demographic variables were calculated. Bivariate and multivariate logistic regression analyses were conducted. Proportions were compared using the Yates' corrected Chi-square test, and a result yielding a p value of less than $5 \%$ was considered statistically significant. Factors that were statistically significantly associated with the outcome on bivariate analyses were considered in a multivariate logistic regression analysis using a backward variable selection method. Odds ratios (unadjusted odds ratios -OR, and adjusted odds ratios - AOR) and their $95 \%$ confidence intervals are reported.

\section{Ethical Considerations}

The study protocol was reviewed by the University of Zambia (UNZA) Biomedical Research Ethics Committee (BREC). Consent was obtained after the interviewer explained among others the purpose of the study, benefits and risks for taking part in the study to the eligible participants. The basic and operational principles of the Helsinki declaration on ethics in research were adhered to in our study. Entry forms were viewed only by approved study personnel.

\section{Results}

Altogether, 1627 persons participated in the survey of which 57.7\% were females. About half (55.9\%) of the participants were aged below 35 years. Male participants tended to have higher education levels than their female counterparts with $32.1 \%$ of males compared to $15.3 \%$ of females having attained college or university level of education. Overall, $32.3 \%$ (33.5\% of males and $31.1 \%$ of females, $\mathrm{p}=0.350$ ) were hypertensive. These results are shown in Table 1.

Table 2 shows factors associated with hypertension in bivariate 
Citation: Siziya S, Rudatsikira E, Babaniyi O, Songolo P, Mulenga D, et al. (2012) Prevalence and Correlates of Hypertension among Adults Aged 25 Years or Older in a Mining Town of Kitwe, Zambia. J Hypertens 1:105. doi:10.4172/2167-1095.1000105

Page 3 of 5

\begin{tabular}{llll}
\hline Factor & $\begin{array}{l}\text { Total } \\
\mathrm{n}(\%)\end{array}$ & $\begin{array}{l}\text { Male } \\
\mathrm{n}(\%)\end{array}$ & $\begin{array}{l}\text { Female } \\
\mathrm{n}(\%)\end{array}$ \\
\hline $\begin{array}{l}\text { Age group (years) } \\
25-34\end{array}$ & $\begin{array}{l}\text { (5) } \\
\text { 35-44 }\end{array}$ & $387(56.8)$ & $512(55.4)$ \\
$45+$ & $347(21.4)$ & $127(18.6)$ & $219(23.7)$ \\
Sex & $366(22.6)$ & $167(24.5)$ & $193(20.9)$ \\
Male & & & \\
Female & $682(42.3)$ & - & - \\
Education & $932(57.7)$ & - & - \\
None & & & $56(6.0)$ \\
Primary & $79(4.9)$ & $22(3.3)$ & $339(36.5)$ \\
Secondary & $505(31.2)$ & $160(23.7)$ & $393(42.3)$ \\
College/university & $675(41.5)$ & $277(41.0)$ & $142(15.3)$ \\
Hypertension & $360(22.2)$ & $217(32.1)$ & \\
Yes & & & $271(31.1)$ \\
No & $504(32.3)$ & $226(33.5)$ & $600(68.9)$ \\
\hline
\end{tabular}

NB: numbers may not add up due to missing information

Table 1: Demographic factors and hypertension prevalence between sexes in Kitwe, Zambia.

analyses. Only age, education, and body mass index were significantly associated with hypertension.

Age and body mass index remained significantly associated with hypertension in a multivariate analysis. Compared to participants who were of age 45 years or older, participants who were below the age of 45 years were less likely to have hypertension $(\mathrm{AOR}=0.53,95 \% \mathrm{CI}[0.45$, $0.62]$ ) for $25-34$ years age group, and $\mathrm{AOR}=0.61,95 \% \mathrm{CI}[0.50,0.74]$ ) for 35-44 years age group). Participants who had BMI of less than 18.5 $\mathrm{kg} / \mathrm{m}^{2}$ were $50 \%$ (AOR $=0.50,95 \%$ CI $\left.[0.32,0.77]\right)$ less likely to have hypertension compared to participants who had BMI of $30 \mathrm{~kg} / \mathrm{m}^{2}$ or more. Meanwhile, participants who had BMI of $25.0-29.9 \mathrm{~kg} / \mathrm{m}^{2}$ were $33 \%(\mathrm{AOR}=1.33,95 \% \mathrm{CI}[1.05,1.69]$ more likely to have hypertension compared to participants who had BMI of $30 \mathrm{~kg} / \mathrm{m}^{2}$ or more. Alcohol, reported sedentary lifestyle and smoking were not found to be associated with high blood pressure.

Overall, $279(55.4 \%)$ out of 504 participants $(81 / 226$ or $35.8 \%$ of males and $198 / 271$ or $70.1 \%$ of females) who were found to be hypertensive during the survey were previously informed by a doctor or health worker that they had raised blood pressure. Currently, $38.5 \%$ of the participants were taking drugs for hypertension, $35.7 \%$ were advised to reduce salt intake, $19.7 \%$ were advised or given treatment to lose weight, and $29.7 \%$ were advised to start or do more exercises (Table 3). The proportions of males and females receiving treatments or advice for hypertension were not significantly different.

\section{Discussion}

In a community-based study of hypertension among adults living in Kitwe, Zambia, we found that about 1 in 3 residents $(31.8 \%)$ had hypertension. This prevalence of hypertension is higher than $22 \%$ reported by Muhihi et al. [8] in Uganda and 23.7\% reported by Muhihi et al. [19] in Tanzania. The difference between our finding and that of Muhihi and colleagues may partly be due to the fact the study by Muhihi and colleagues was conducted in a rural area, while our study was conducted in an urban area. Sedentary lifestyles, a risk factor for hypertension [20] is more likely to be prevalent in urban than rural areas. That cannot be the case for the Muhihi et al. study since it was conducted in the City of Mwanza. The difference between our finding and that of Muhihi and colleagues may partly be due to cultural background such as diet differences.

\begin{tabular}{|c|c|}
\hline Factor & OR $(95 \% \mathrm{Cl})$ \\
\hline \multicolumn{2}{|l|}{ Age group (years) } \\
\hline $25-34$ & $0.49(0.42,0.57)$ \\
\hline $35-44$ & $0.65(0.54,0.78)$ \\
\hline $45+$ & 1 \\
\hline \multicolumn{2}{|l|}{ Sex } \\
\hline Male & $1.06(0.95,1.18)$ \\
\hline Female & 1 \\
\hline \multicolumn{2}{|l|}{ Education } \\
\hline None & $2.11(1.49,2.99)$ \\
\hline Primary & $0.99(0.82,1.20)$ \\
\hline Secondary & $0.56(0.46,0.68)$ \\
\hline College/university & 1 \\
\hline \multicolumn{2}{|c|}{$\begin{array}{l}\text { Time usually spent sitting or reclining on a typical day } \\
\text { (hours) }\end{array}$} \\
\hline$<1.5$ & $1.07(0.90,1.29)$ \\
\hline $1.5-3.4$ & $0.89(0.76,1.03)$ \\
\hline $3.5+$ & 1 \\
\hline \multicolumn{2}{|c|}{ Body mass index $\left(\mathrm{kg} / \mathrm{m}^{2}\right)$} \\
\hline$<18.5$ & $0.49(0.32,0.74)$ \\
\hline $18.5-24.9$ & $0.75(0.61,0.91)$ \\
\hline 25.0-29.9 & $1.38(1.11,1.72)$ \\
\hline $30+$ & 1 \\
\hline \multicolumn{2}{|c|}{ Alcohol consumption } \\
\hline Yes & $1.16(0.90,1.48)$ \\
\hline No & 1 \\
\hline \multicolumn{2}{|l|}{ Cigarette smoking } \\
\hline Yes & $1.06(0.88,1.27)$ \\
\hline No & 1 \\
\hline \multicolumn{2}{|l|}{ Waist-Hip ratio } \\
\hline$\leq 1$ & $0.75(0.55,1.04)$ \\
\hline$>1$ & 1 \\
\hline \multicolumn{2}{|c|}{ Heart rate (beats per minute) } \\
\hline$<60$ & $0.99(0.66,1.50)$ \\
\hline $60-90$ & $0.97(0.77,1.23)$ \\
\hline$>90$ & 1 \\
\hline
\end{tabular}

OR Odds ratio; $\mathrm{Cl}$ Confidence interval

Table 2: Factors associated with hypertension in bivariate analyses in Kitwe Zambia.

\begin{tabular}{llll}
\hline Factor & $\begin{array}{l}\text { Total } \\
\mathrm{n}(\%)\end{array}$ & $\begin{array}{l}\text { Male } \\
\mathrm{n}(\%)\end{array}$ & $\begin{array}{l}\text { Female } \\
\mathrm{n}(\%)\end{array}$ \\
\hline $\begin{array}{l}\text { Took drugs in past } 2 \text { weeks } \\
\text { Yes }\end{array}$ & $\begin{array}{l} \\
107(38.5)\end{array}$ & $\begin{array}{l}33(40.7) \\
74(37.6)\end{array}$ \\
$\begin{array}{l}\text { No } \\
\text { Advice to reduce salt intake }\end{array}$ & $99(35.7)$ & $31(38.3)$ & $68(34.7)$ \\
Yes & $178(64.3)$ & $50(61.7)$ & $128(65.3)$ \\
No & & & \\
Advice or treatment to lose weight & $55(19.7)$ & $13(16.0)$ & $42(21.2)$ \\
Yes & $224(80.3)$ & $68(84.0)$ & $156(78.8)$ \\
No & & & \\
Advice to start or do more exercises & $82(29.7)$ & $27(33.8)$ & $55(28.1)$ \\
Yes & $194(70.3)$ & $53(66.3)$ & $141(71.9)$ \\
No & &
\end{tabular}

NB: numbers may not add up due to missing information

Table 3: Treatment/advice given to participants for high blood pressure between sexes in Kitwe, Zambia. 
In this study, there was no significant gender difference in the prevalence of hypertension. This finding is inconsistent with findings from another urban setting in Zambia, namely Lusaka, the capital city, where Goma et al. [11] found that males were more likely to have hypertension than females. In Tanzania, Njelekela et al. [21] found that males were more at risk of hypertension than females, while Wamala et al. [22] reported the opposite from Uganda. The finding in Tanzania that females were less likely to have hypertension than males may partly be due to females having tended to have higher physical activity than males [21]. Meanwhile in Uganda, Bimenya et al. [23] have reported that many people in Uganda tended to adopt "western type" diet and sedentary life styles that facilitate fat accumulation. The diet and sedentary life styles may have different effects in males and females such that a greater degree of adiposity may be achieved in females than males that may in turn lead to higher rates of hypertension in females than males.

That increasing age was positively associated with high blood pressure is consistent with findings from previous studies from other sub-Saharan African countries such as Sierra Leone [6], Ethiopia [7], Uganda [8], and Cameroon [24]. Increasing age is a recognized risk factor for hypertension, affecting approximately $70 \%$ of those over 65 years of age [25].

Participants who had BMI of less than 25 were less likely to have hypertension than those who had BMI of 30 or more, which is consistent with previous studies that have reported a strong association between hypertension and BMI $[11,26]$. However, we found that participants with overweight BMIs had higher prevalence of hypertension than participants with obese BMI. It is likely that obese people may seek medical attention in order to control their obesity, and in turn reduce their chances of being hypertensive. In Malawi, women perceived large body shapes as a sign of being healthy [27], and if the same perception prevailed in our study then overweight people may have perceived overweight as not a problem and would not have adopted life styles to enable them lose weight that might have lead to hypertension.

In Bivariate analysis, participants with no formal education were more than twice likely to have hypertension than those who had college/ university level education. Previous studies have reported the positive relationship between hypertension and low education $[9,10]$. Such association may be due to lack of awareness of risk factors of hypertension [28], improper diet, and lack of access to medical care [10].

We found no association between alcohol, smoking and sedentary life style on one hand and hypertension on the other. Previous studies have reported a differential effect of alcohol drinking depending on drinking patterns with a protective effect of moderate consumption and exacerbating effect of abuse of alcohol [29-31]. The reasons for the lack of association are unclear to us, but could include misclassification of these variables. Another explanation could be the doses of these exposures which may not be enough to be associated with hypertension.

We found that $70.1 \%$ of females and to $35.8 \%$ of males were informed that they were hypertensive by a doctor or other health worker. Females have more access to health services through attending antenatal care and other services than males have. However, both sexes were accorded equal access to treatment for hypertension.

\section{Limitations}

This study has several limitations. The cross sectional nature precludes the ability to ascribe causation. Secondly, some of the data such as education level and age were self-reported. To the extent that the study participants may have misreported, our findings may be biased. We also did not evaluate other risk factors for hypertension such as psychosocial stress that are known to be associated with hypertension $[32,33]$. We also used unweighted analysis because we were unable to compute weights because we did not obtain information to enable us to compute response rates.

\section{Conclusions}

Our findings indicate that hypertension is prevalent among urban residents in Kitwe, Zambia. Effective prevention strategies should be implemented, taking into considerations the risk factors identified in this study.

\section{References}

1. http://www.who.int/healthinfo/EN_WHS2012_Full.pdf

2. Franco $\mathrm{OH}$, Peeters A, Bonneux L, de Laet C (2005) Blood pressure in adulthood and life expectancy with cardiovascular disease in men and women life course analysis. Hypertension 46: 280-286.

3. Jamison DT, Feachem RG, Magkoba MW, Bos ER, Baingana FK, et al (2006) Disease and Mortality in Sub-Saharan Africa, 2nd edition. World Bank Washington DC.

4. Bloom DE, Cafiero ET, Jané-Llopis $E$, Abrahams-Gessel S, Bloom LR, et al. (2011) The Global Economic Burden of Non-communicable Diseases. Geneva: World Economic Forum.

5. Smith SM, Mensah GA (2003) Population aging and implications for epidemic cardiovascular disease in Sub-Saharan Africa. Ethn Dis 13: S77-80.

6. Meehan KA, Bankoski AJ, Tejan E, Ansumana R, Bangura U, et al. (2011) Hypertension in Bo, Sierra Leone. Ethn Dis 21: 237-242.

7. Giday A, Tadesse B (2011) Prevalence and determinants of hypertension in rural and urban areas of southern Ethiopia. Ethiop Med J 49: 139-147.

8. Maher D, Waswa L, Baisley K, Karabarinde A, Unwin N (2011) Epidemiology of hypertension in low-income countries: a cross-sectional population-based survey in rural Uganda. J Hypertens 29: 1061-1068.

9. Hoang VM, Byass P, Dao LH, Nguyen TK, Wall S (2007) Risk factors for chronic disease among rural Vietnamese adults and the association of these factors with sociodemographic variables: findings from the WHO STEPS survey in rural Vietnam, 2005. Prev Chronic Dis 4: A22.

10. Grotto I, Huerta M, Sharabi Y (2008) Hypertension and socioeconomic status. Curr Opin Cardiol 23: 335-339.

11. Goma FM, Nzala SH, Babaniyi O, Songolo P, Zyaambo C, et al. (2011) Prevalence of hypertension and its correlates in Lusaka urban district of Zambia: a population-based survey. Int Arch Med 4: 34.

12. McGavock JM, Anderson TJ, Lewanczuk RZ (2006) Sedentary lifestyle and antecedents of cardiovascular disease in young adults. Am J Hypertens 19: 701-707.

13. Shi $Y$, de Groh M, Morrison $H$ (2012) Increasing blood pressure and its associated factors in Canadian children and adolescents from Canadian Health Measures Survey. BMC Public Health 12: 388

14. Cameron VA, Faatoese AF, Gillies MW, Robertson PJ, Huria TM, et al. (2012) A cohort study comparing cardiovascular risk factors in rural Maori, urban Maori and non-Maori communities in New Zealand. BMJ Open 2.

15. Shimomura T, Wakabayashi I (2012) Associations of cardiovascular risk factors with prehypertension and hypertension in women. Blood Press.

16. Sacks FM, Svetkey LP, Vollmer WM, Appel LJ, Bray GA, et al. (2001) Effects on blood pressure of reduced dietary sodium and the Dietary Approaches to Stop Hypertension (DASH) diet. DASH-Sodium Collaborative Research Group. N Engl J Med 344: 3-10.

17. Nsakashalo-Senkwe M, Siziya S, Goma FM, Songolo P, Mukonka V, et al. (2011) Combined prevalence of impaired glucose level or diabetes and its correlates in Lusaka urban district, Zambia: a population based survey. Int Arch Med 4:2. 
Citation: Siziya S, Rudatsikira E, Babaniyi O, Songolo P, Mulenga D, et al. (2012) Prevalence and Correlates of Hypertension among Adults Aged 25 Years or Older in a Mining Town of Kitwe, Zambia. J Hypertens 1:105. doi:10.4172/2167-1095.1000105

18. World Health Organization (2005) The WHO STEPS Surveillance Manual: WHO STEPwise approach to chronic disease risk factor surveillance. World Health Organization, Geneva.

19. Muhihi A, Njelekela M, Mpembeni R, Masesa Z, Kitamori K, et al. (2012) Physical activity and cardiovascular disease risk factors among young and middle-aged men in urban Mwanza, Tanzania. Pan Afr Med J 11: 11.

20. Tringler M, Rodriguez EM, Aguera D, Molina JD, Canziani GA, et al. (2012) High blood pressure, overweight and obesity among rural scholars from the vela project: a population-based study from South america. High Blood Press Cardiovasc Prev 19: 41-46.

21. Njelekela MA, Mpembeni R, Muhihi A, Mligiliche NL, Spiegelman D, et al (2009) Gender-related differences in the prevalence of cardiovascular disease risk factors and their correlates in urban Tanzania. BMC Cardiovasc Disord 9: 30 .

22. Wamala JF, Karyabakabo Z, Ndungutse D, Guwatudde D (2009) Prevalence factors associated with hypertension in Rukungiri district, Uganda--a community-based study. Afr Health Sci 9: 153-160.

23. Bimenya GS, Okot JK, Nangosa H, Anguma SA, Byarugaba W (2006) Plasma cholesterol and related lipid levels of seemingly healthy public service employees in Kampala, Uganda. Afr Health Sci 6: 139-144.

24. Shey Wiysonge CU, Ngu Blackett K, Mbuagbaw JN (2004) Risk factors and complications of hypertension in Yaounde, Cameroon. Cardiovasc J S Afr 15: 215-219.

25. Yoon PW, Gillespie CD, George MG, Wall HK; Epidemiology and Analysis Program Office, et al. (2012) Control of hypertension among adults - national health and nutrition examination survey, United States, 2005-2008. MMWR Surveill Summ 61: 19-25.
26. Humayun A, Shah AS, Sultana R (2009) Relation of hypertension with body mass index and age in male and female population of Peshawar, Pakistan. $J$ Ayub Med Coll Abbottabad 21: 63-65.

27. Bentley ME, Corneli AL, Piwoz E, Moses A, Nkhoma J, et al. (2005) Perceptions of the role of maternal nutrition in HIV-positive breast-feeding women in Malawi. J Nutr 135: 945-949.

28. Samal D, Greisenegger S, Auff E, Lang W, Lalouschek W (2007) The relation between knowledge about hypertension and education in hospitalized patients with stroke in Vienna. Stroke 38: 1304-1308.

29. Corrao G, Rubbiati L, Bagnardi V, Zambon A, Poikolainen K (2000) Alcohol and coronary heart disease: a meta-analysis. Addiction 95: 1505-1523.

30. Ronksley PE, Brien SE, Turner BJ, Mukamal KJ, Ghali WA (2011) Association of alcohol consumption with selected cardiovascular disease outcomes: a systematic review and meta-analysis. BMJ 342: d671.

31. Mukamal KJ, Conigrave KM, Mittleman MA, Camargo CA Jr, Stampfer MJ, et al. (2003) Roles of drinking pattern and type of alcohol consumed in coronary heart disease in men. $\mathrm{N}$ Engl J Med 348: 109-118.

32. Bansal SK, Saxena V, Kandpal SD, Gray WK, Walker RW, et al. (2012) The prevalence of hypertension and hypertension risk factors in a rural Indian community: A prospective door-to-door study. J Cardiovasc Dis Res 3: 117 123.

33. Ginty AT, Carroll D, Roseboom TJ, Phillips AC, de Rooij SR (2012) Depression and anxiety are associated with a diagnosis of hypertension 5 years later in a cohort of late middle-aged men and women. J Hum Hypertens. 